\title{
REPEAT-PASS INTERFEROMETRIC AND BACKSCATTER ANALYSIS OF X-BAND PAZ SATELLITE - FIRST RESULTS
}

\author{
S. Abdikan ${ }^{1 *}$, C. Bayik ${ }^{1}$, M. Ustuner ${ }^{2}$, F. Balik Sanli ${ }^{2}$, \\ ${ }^{1}$ Dept. of Geomatics Engineering, Zonguldak Bulent Ecevit University, Zonguldak, Turkey - (caglarbayik, sabdikan)@ beun.edu.tr \\ ${ }^{2}$ Dept. of Geomatic Engineering, Yildiz Technical University, Istanbul, Turkey - (fbalik, mustuner)@ yildiz.edu.tr
}

Commission III, WG III/2

KEY WORDS: PAZ, SAR, Repeat-pass InSAR, Coherence, Subsidence

\begin{abstract}
:
In this paper we present the initial results of PAZ Synthetic Aperture Radar (SAR) imagery for the first time. In the study, the potential of repeat-pass high resolution PAZ images were investigated. To this aim, both linear backscatter and interferometric results were presented. We used multi-temporal X-band (3.1 cm wavelength) new generation single look complex (SLC) data from Spanish PAZ in single polarization data. PAZ is based on TerraSAR-X/TanDEM-X platform to establish a constellation with them to shorten the revisit time and increase data acquisition capacity. We applied two analysis on PAZ data to assess the performance of the satellite images. For the analysis a semi-arid and almost flat region of Central Anatolia was selected. The images are acquired in both ascending and descending orbits. Each pair has 33 days of temporal baselines. Firstly, backscatter analysis was conducted over the region for different land cover classes. Secondly interferometric analysis was applied to determine phase difference and coherence features. As the region has sand dunes, bareland and uncultivated agricultural fields the coherence analysis showed high values, while cultivated fields showed variations of coherence due to different growth of vegetation. Since the region is prone to sinkhole formation the high-resolution PAZ indicated its advantage as determining a sinkhole that has a circle shape. The displacement of ground surface is determined in line of sight direction.
\end{abstract}

\section{INTRODUCTION}

The repeat-pass Interferometric SAR (InSAR) acquisitions developed to estimate displacement over the Earth surface. The main advantages is its weather independent, and day and night image acquisition abilities. It is a well-established technique and reveals accurate measurements to determine displacements and topography estimation. New generation SAR satellites have the ability to acquire higher spatial resolution images and within shorter revisit periods. Meanwhile, some of them composed constellations to increase the revisit time which developed new applications, rapid response to natural hazards and long term monitoring using time series analysis (Moreira et al., 2013, Xue et al., 2020).

The PAZ is a new satellite which carries X-band SAR sensor operating at $9.65 \mathrm{GHz}$ launched on February 2018 by Hisdesat, Spain (Hisdesat, 2019). Previous studies have been presented the contribution of X-band satellites, e.g. TerraSAR-X satellite operating with eleven-day repeat orbit was launched in 2007. It has also been used for short term displacement analysis such as landslides (Du et al., 2017) and earthquakes (Motagh et al., 2013). It has been also widely used for long term slowly developed surface movements (Calo et al., 2015), volcano activities (Richter et al., 2013) and railway monitoring (Luo et al., 2017). Additionally, its twin satellite TanDEM-X was launched in 2010. It is aimed to generate high precision Digital Elevation Model (DEM) using single-pass bistatic interferometric acquisition of TerraSAR-X/Tandem-X (Schlund et al., 2014).
Italian Space Agency has been conducted X-band Earth observation COSMO-SkyMed satellite system, which was constituted by four satellites to increase the repeat orbit (Bovenga et al. 2012). Korea Aerospace Research Institute launched X-band Kompsat-5 SAR satellite in 2013. Considering other X-band satellites, Kompsat-5 does not provide shorter orbital repeat with 28 days, but it provides highresolution images as others (Lee 2010).

As a new generation X-band SAR satellite, PAZ is compatible with TerraSAR-X and, is aimed to establish a constellation with it to increase the data acquisition capacity while shortening the revisit time. Within this scope, both satellite will operate in the same orbit that provides an opportunity to shorten the revisit time to 4 and 7 days for interferometric purposes (Bach et al., 2018) while each satellite (TerraSAR-X or PAZ) has 11 days revisit time. Identical imaging modes of two missions will also provide a high resolution SAR constellation.

It has four imaging modes that are StripMap (SM), ScanSAR (SC), Spotlight (SL) and High Resolution Spotlight (HS) modes. Except for ScanSAR mode, it can provide both single and dual polarized images. Two more modes as Wide ScanSAR in single polarization and Staring Spotlight modes in single polarization and up to $25 \mathrm{~cm}$ resolution will be also included. These modes provide images having spatial resolutions ranging from $1 \mathrm{~m}$ to $18 \mathrm{~m}$ (Hisdesat, 2019).

\footnotetext{
* Corresponding author
} 
In this study, we present our first experimental results of the potential usage of X-band PAZ for the repeat pass interferometric applications. In this work, we focused on a fragile region in the centre of Konya Plain, Turkey. The study region has different geological, archaeological and cultural areas. Distributed volcanic shapes and related tectonic path are situated in this area. Climate condition is mostly semi-arid and with the effect of wind sand form can move and sand dunes, barchans structures can be seen. As one of Turkey's most important agricultural production region, the basin has an important share in agricultural production like grain, pulses, and sugar beet. Konya is one of the most affected regions of Turkey from drought and global climate. The main treatment is agricultural irrigation but it is not sustainable in the region.

Dense agricultural activities have caused an increase in water consumption and, due to the illegal well usage water level is decreasing every year. The geological character of the plain is composed of unconsolidated clay, silt, sandstone, limestone, volcanic land forms and, karstic structures. The karstic depression cause the phenomena sinkhole which is widely seen in this region (Ozdemir, 2015). Sinkholes occur rapidly and it is not easy to estimate their locations before appeared. When a sinkhole occurs, it causes a geometric shape which is a circle or ellipse on surface. This region suffers for the last thirty years from sinkholes and, many of them occurred in the different sizes and depths (Ozdemir, 2015, Orhan et al., 2017). As an unpredictable phenomenon sinkholes threat human life, and cause deterioration of agricultural activities and affect social life negatively.

As the regions are prone to geological hazard, Earth surface subsidence occurs frequently. Our previous study applying small baseline InSAR approach by ENVISAT dataset in this region concluded that the region has a slow displacement over the long term monitoring (Calo et al., 2017). The study indicated approximately $1.5 \mathrm{~cm} / \mathrm{yr}$ deformation between 2002 and 2010. The results also demonstrated that the deformation is dominated at vertical direction. However, due to its rapid occurrence and smaller width of size comparing to ENVISAT resolution it was not possible to extract deformation form and value. To this aim, high resolution PAZ images were tested over the same region for the first time within this study.

\section{MATERIALS AND METHODS}

\subsection{Study Area}

The study area is in the district of Konya city, located in the closed basin of Central Anatolia, Turkey. The entire region is mostly flat. Due to dense agricultural activities and its arid and semi-arid climate conditions, the water consumption has been increased (Calo et al., 2017). The study area is shown in Figure 1. This region includes different morphological structures such as sand dune, volcanic structures and sinkhole (Dogan and Yilmaz 2011).

Diverse sinkholes which have diameters reaching up to 64 meters are distributed in the region (Dogan and Yilmaz 2011, Orhan et al., 2017). For this region it is indicated that sinkholes occurrence probability increases with the increase of fault density (Ozdemir, 2015). Sand dunes are located at the south of the city, while volcanic structures are located at the south and south east of Karapinar district. Agricultural fields are mostly located on the west and north of the city. In the study area there is also a region where sparse vegetation is located where also sand dunes located.
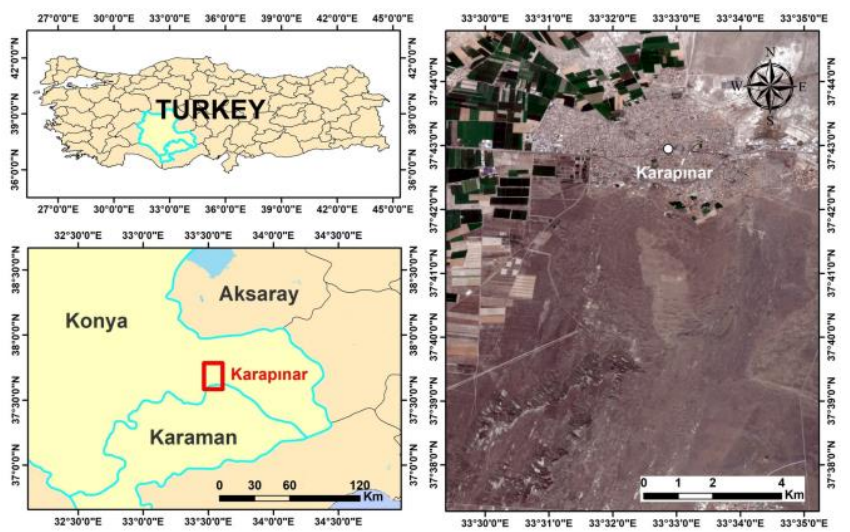

Figure 1 . The study area

\subsection{PAZ satellite data}

One pair of ascending and one pair of descending images of PAZ were available for the analysis. They cover same period but different orbit acquisitions (Table 1). Ascending and descending images' incidence angles are close to each other, $37.39^{\circ}$ and $35.28^{\circ}$ respectively. The range spacing is $0.91 \mathrm{~m}$ and the azimuth spacing is $1.99 \mathrm{~m}$. The images are acquired in Single Look Complex (SLC) format in StripMap mode.

\begin{tabular}{|l|l|}
\hline Specifications & Description \\
\hline Sensor & PAZ \\
Wavelength & X-band \\
Frequency & $9.65 \mathrm{GHz}$ \\
Imaging mode & StripMap \\
Orbit & Asc \& Des \\
Incidence Angle $\left(^{\circ}\right)$ & $37.39^{\circ}($ Asc $)$ \\
& $35.28^{\circ}($ Desc) \\
Resolution $($ Rg x Az) & $0.91 \times 1.99(\mathrm{~m})$ \\
Polarization & Single-Pol (VV) \\
Nominal acquisition direction & Right looking \\
\hline
\end{tabular}

Table 1. Technical characteristics of PAZ

For the sensitivity analysis of the backscatter and coherence, different land cover types were analysed utilizing a multitemporal analysis. For this purpose four remotely sensed VV polarized Stripmap mode of PAZ SAR data were acquired on 09 October, 13 October, 11 November and 15 November in 2019. Pre-processing steps were performed consecutively as radiometric calibration, noise removal, multilooking and topographic correction using Range Doppler Terrain Correction with SRTM 1Sec HGT data and co-registration were performed with open source tools of Sentinel Application Platform (SNAP) software. As a last step of the pre-processing chain, pixel backscatter coefficient $\left(\sigma^{\circ}\right)$ was converted to sigma nought in decibel $(\mathrm{dB})$ using the equation 1 .

$\sigma_{\mathrm{dB}}=10 \cdot \log _{10}\left(\sigma^{\circ}\right)$

The behaviour of scattering depends on the physical properties of the terrain, primarily the geometry and electromagnetic properties of the terrain elements. The pre-processing steps of 
SAR images to determine interferogram, coherence and displacement images are presented in Figure 2.

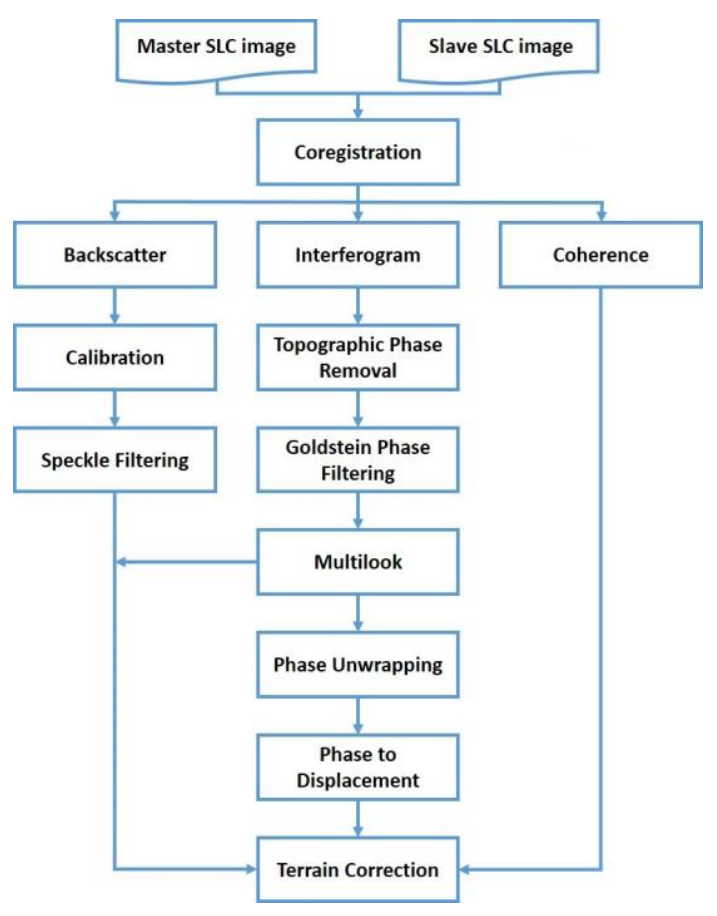

Figure 2. Flowchart of the pre-processing steps

\subsection{Interferometric analysis}

Space-borne satellite based repeat pass Synthetic Aperture RADAR (SAR) data have ability to determine displacement of the Earth surface in millimetre level. Differential SAR Interferometry (DInSAR) exploits phase measurements at range direction and determine the deformation occurs at Line of Sight (LOS) direction. It uses phase difference of two SAR images which cover the same region. For the detection of displacement images should be acquired different times. Temporal decorrelation is the most prominent fact that occurs while the temporal baseline increases between the repeat-pass InSAR acquisitions (Moreira et al., 2013). Especially the regions covered by vegetation might changes in long term can cause to decorrelation. In DInSAR analysis it is also expected an interferogram that has shorter geometrical baseline not to have decorrelation. (Xue et al., 2020).

DInSAR technique has indicated its benefits for the identification of surface displacement in different applications such as Deguchi et al. (2007) indicated mining related subsidence using C-band Radarsat-1 and L-band ALOS-1 PALSAR data. Even they determined enough coherence and phase information over the residential area it is also mentioned that C-band fails over the vegetated area. On the other hand Lband provided higher coherence and determined displacement over the vegetated regions over the underground mining. Abdikan et al. (2019) demonstrated the DInSAR results of Cband Sentinel-1after an earthquake. Shorter revisit period of Sentinel-1 provided displacement in both ascending and descending orbit acquisitions. Milillo et al. (2014) presented potential of X-band COSMO-SkyMed data over landslides that was developed rapidly. It is indicated that daily acquisition of image pair can provide evolution of displacement. Nof et al. (2013) showed the precursory deformation due to sinkhole that can be detected using high resolution X-band COSMO-SkyMed data.

For the subsidence extraction, the following steps were applied as coregistration, interferogram generation, topographic effect removal, phase filtering, multilooking, unwrapping, phase to displacement conversion and terrain correction. Goldstein filter was applied to smooth the phase. SRTM 1Sec HGT data was used for the topographic effect removal and Range Doppler Terrain Correction. A statistical-cost network-flow approach of phase unwrapping called SNAPHU was applied to convert the unwrapped phase to displacement values. The extracted values are in the LOS direction. The phase differences of pairs were used to compose $\Phi_{\text {int }}$ interferogram as follows (Xue et al., 2020):

$\Phi_{\text {int }}=\Phi_{\text {flat }}+\Phi_{\text {dem }}+\Phi_{\text {def }}+\Phi_{\text {aps }}+\Phi_{\text {noise }}$

where $\Phi_{\text {flat }}=$ Earth flat phase component,

$\Phi_{\mathrm{dem}}=$ topographic component

$\Phi_{\text {def }}=$ deformation phase

$\Phi_{\text {aps }}=$ atmospheric phase delay

$\Phi_{\text {noise }}=$ random noise

As a potential analysis of PAZ satellite on interferometric applications we evaluate coherence products of the image pairs. Coherence is one of the parameters that shows the performance of the interferometric process. Coherence represents the crosscorrelation coefficient between two coregistered complex images and represented as $\gamma$. It ranges from 0 (no correlation) to 1.0 (a perfect correlation) and shows how two pixel look alike. Multi-date coherence can be used to identify land cover classes and change detection analysis (Moreira et al., 2013). Similar to interferogram, coherence also might be affected by different sources such as temporal and geometrical baselines. Compared to amplitude sensitivity of coherence to changes is higher due to having both phase and amplitude components of the radar signal.

Coherence can be expressed by $\gamma$ and calculated as follows (Antonova et al. 2018):

$\gamma=\frac{\left|\left\langle S_{1} S_{2}^{*}\right\rangle\right|}{\sqrt{\left(\left(S_{1} S_{1}^{*}\right\rangle\left\langle S_{2} S_{2}^{*}\right\rangle\right)}}$

where $\mathrm{S} 1$ and $\mathrm{S} 2=$ complex matrices of backscatter coefficient of the SAR image pair

$*$ = complex conjugation

$\diamond>=$ indicates spatial averaging

\section{RESULTS AND DISCUSSION}

\subsection{Backscatter analysis}

Based on the backscatter values, the city appears very bright and has high backscatter values as expected. The backscatter images are represented in Figure 3 with RGB colour composite for the visual interpretation. On the other hand, these values 
overlap with the backscatter values of bareland and uncultivated agricultural regions. Agricultural areas differ due to different crop products physical characteristics in terms of backscatter values.

The region is almost flat, but south of the city has sand dunes and barchans structures. Due to the having both ascending and descending acquisition modes in these parts, the backscattering differs from each other due to their different look angle direction. Especially the ridges of the barchans appears different in these images. In the ascending images they have higher backscatter values at the western side, while in the descending images they have higher values at the eastern side of the barchans due to their direction through the satellite. Some statistics regarding to the ascending and descending acqusitions are provided in Table 2 .
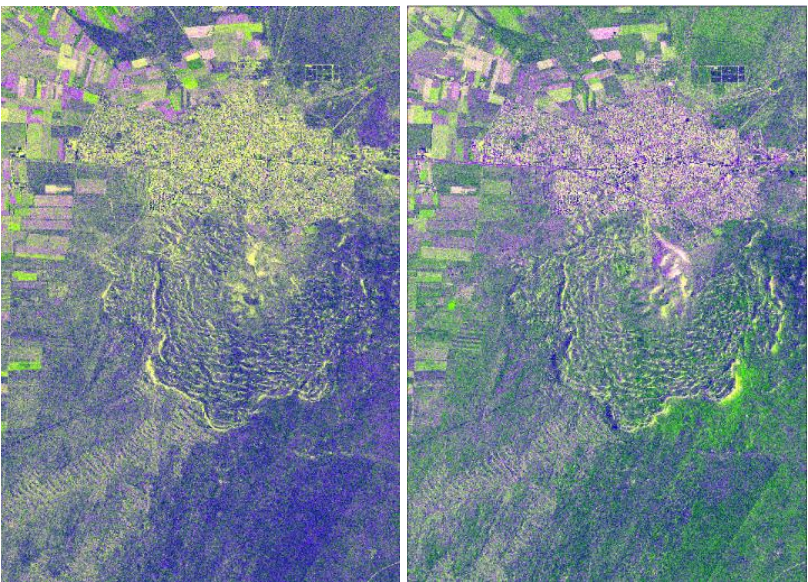

Figure 3. Backscatter images a) ascending (RGB: 09Oct, 11 Nov, difference of $09 \mathrm{Oct}$ and $11 \mathrm{Nov}$ ), b) descending (RGB: 13 Oct, 15 Nov, difference of 13 Oct and $15 \mathrm{Nov}$ ). PAZ satellite image () Hisdesat Servicios Estratégicos S.A., 2019.

\begin{tabular}{|lllll|}
\hline Date & $\begin{array}{l}\text { Min } \\
(\mathbf{d B})\end{array}$ & $\begin{array}{l}\text { Max } \\
(\mathbf{d B})\end{array}$ & $\begin{array}{l}\text { Mean } \\
(\mathbf{d B})\end{array}$ & $\begin{array}{l}\text { Std Dev } \\
(\mathbf{d B})\end{array}$ \\
\hline 09 Oct 2019 (Asc) & -29.76 & 30.15 & -14.45 & 3.85 \\
11 Nov 2019 (Asc) & -30.79 & 29.77 & -14.87 & 3.91 \\
13 Oct 2019 (Desc) & -28.48 & 31.59 & -14.07 & 3.76 \\
15 Nov 2019 (Desc) & -28.55 & 29.94 & -10.55 & 3.17 \\
\hline
\end{tabular}

Table 2. Statistics of the images

\subsection{InSAR results}

In the second case, SAR interferometry was applied to extract coherence map and possible surface deformation. The ascending pair of 09 October and 11 November dated images has $98 \mathrm{~m}$ perpendicular baseline and 33 days temporal baseline. The descending pair 13 October and 15 November dated images have $170 \mathrm{~m}$ perpendicular baseline and 33 days temporal baseline (Table 3). A multilook of two at the range and two at azimuth was applied to obtain filtered and smoothed image for further analysis. The final product has a $3 \mathrm{~m} \times 3 \mathrm{~m}$ spatial resolution. The coherence maps were produced from both ascending and descending pairs.
It is expected to have higher coherence where the values of the pixels should be close to one. In the result, generally urban and sand dune appear brighter than the other objects. On the other hand, agricultural parts which have angular and proper shapes have lowest coherence values and appear dark grey to black in the coherence maps (Figure 3).

\begin{tabular}{|c|cc|}
\hline Master image & 13 Oct 2019 & 09 Oct 2019 \\
Slave image & 15 Nov 2019 & 11 Nov 2019 \\
Orbit & Descending & Ascending \\
Bperp (m) & 170 & 98 \\
Btemp (days) & 33 & 33 \\
\hline
\end{tabular}

Table 3. PAZ image pairs

The coherence values ranges between 0.003 and 0.998 for the ascending and, 0.015 and 0.991 for the descending results in general (Figure 4). For the selected regions of interests coherence values were extracted. As expected, residential areas provided high average of coherence values as 0.70 and 0.51 in the ascending and descending coherence maps. Sand dunes are the characteristic structure in the region and generally they have high coherence values as urban and bare land. Average coherence values range from 0.16 to 0.91 in ascending and from 0.02 to 0.71 in descending results.

Agricultural fields located at the north-west of images. The phenological stages of agricultural growth varies in the field and denser crops have low values of coherence. Sparse vegetation crops present higher coherence over 33 day of revisit cycles (Table 4). The general difference in coherence products might be due to the acquisition modes that effect the response where relief of surface structures changes.

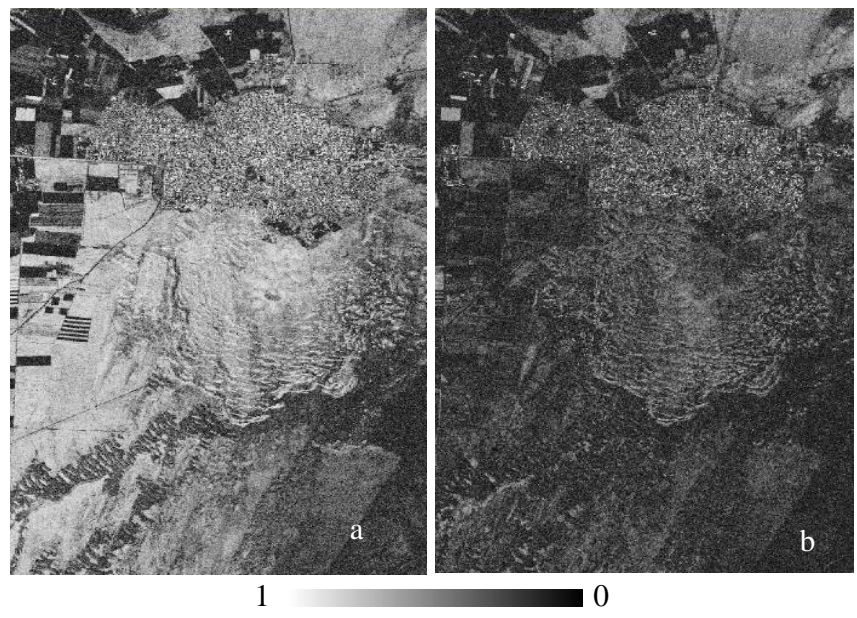

Figure 4. Coherence images of the pairs a) ascending, b) descending. (PAZ satellite image (C) Hisdesat Servicios Estratégicos S.A., 2019.)

In both ascending and descending pairs of interferograms indicate deformation patterns as shown in the Figure 5. Two displacement pattern shown in the black circles located at the 
north and south of the images. As noticed the displacement is clearly visible in both results.

\begin{tabular}{|l|lll|lll|}
\hline Coherence & \multicolumn{3}{|c|}{ Ascending } & \multicolumn{3}{c|}{ Descending } \\
& Min & Mean & Max & Min & Mean & Max \\
\hline Urban & 0.03 & 0.70 & 0.99 & 0.03 & 0.51 & 0.98 \\
Bareland & 0.17 & 0.24 & 0.88 & 0.04 & 0.54 & 0.83 \\
Sparse veg & 0.14 & 0.27 & 0.70 & 0.02 & 0.19 & 0.58 \\
Sand dune & 0.16 & 0.73 & 0.91 & 0.02 & 0.28 & 0.71 \\
Uncultivated & 0.23 & 0.77 & 0.93 & 0.01 & 0.22 & 0.65 \\
\hline
\end{tabular}

Table 4. Coherence values for the selected ROIs



090ct2019_11Nov2019



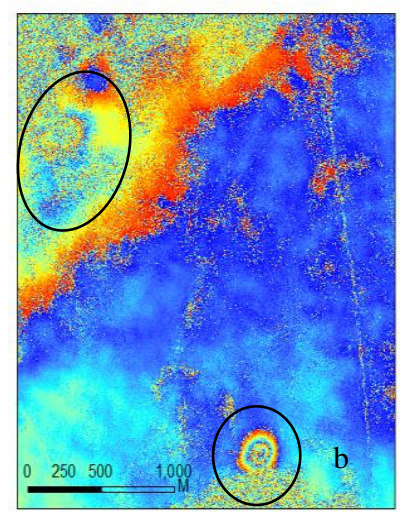

130ct2019_15Nov2019

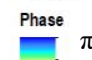

$\pi$

Figure 5. Interferograms of pairs a) ascending, b) descending

The results of repeat-pass InSAR indicated that approximately 4 $\mathrm{cm}$ and $4.5 \mathrm{~cm}$ displacement value was determined for a small pattern of sinkhole which has a wide of $200 \mathrm{~m}$ diameter and has in ascending and descending results, respectively (Figure 6). Even with the average coherence values within the $200 \mathrm{~m}$ diameter were 0.31 in descending and 0.2 in ascending coherence maps small scale displacement were identified.

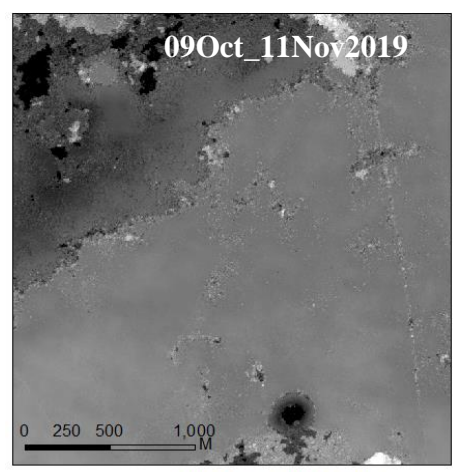

Displacement in LOS Value

$0.045 \mathrm{~m}$ $-0.053 \mathrm{~m}$

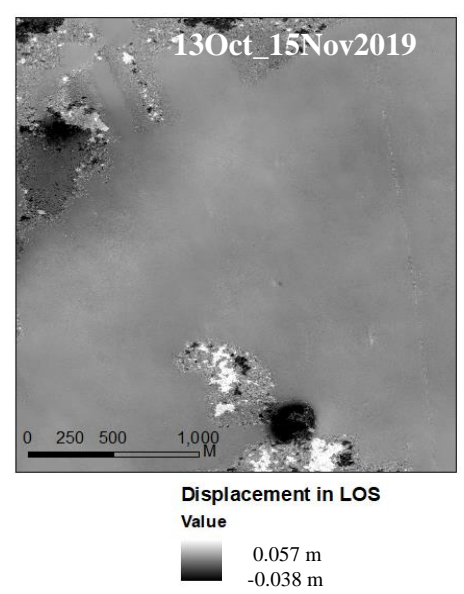

Figure 6. Displacement values in LOS

\section{CONCLUSION AND FUTURE PERSPECTIVES}

This study investigates the potential of new X-band satellite PAZ. Backscatter values and interferometric products were analysed for the selected region where is prone to surface subsidence. To this aim, coherence and DInSAR products were created for the images acquired in 33 days interval.

As noticed in our experimental results, local and small scale deformation pattern can be extracted by high resolution repeat pass SAR images of PAZ satellite even with one month revisit period. Using multi-temporal data can be used to monitor for long time period to understand the dynamics of the phenomenon. Our initial results strongly encourage the repeat pass InSAR of X-band PAZ SAR data to take precaution for sinkhole monitoring which plays a relevant role for risk assessment.

Future works include multi-temporal SAR acquisition and time series analysis including different seasons. Textural features will be incorporated to improve the accuracy of land cover classification results as a follow-up study. It is also planned to apply decomposition of ascending and descending results to determine horizontal and vertical movement in space. New data with shorter temporal baseline will demonstrate how the coherence and interferogram will be developed in shorter time period.

\section{Acknowledgements}

The authors would like to thank to INTA-PAZ Science Team for providing the PAZ data in the framework of "AO-001-031" project.

\section{References}

Abdikan S., Imamoglu M., Alasag T., Toker M., Kutoglu S.H., Sahin S., INSAR Analysıs of Ayvac1k 2017 (Mw 5.3) Earthquake Swarm (Canakkale, Nw-Turkey), Int. Arch. Photogramm. Remote Sens. Spatial Inf. Sci., XLII-2/W13, 1907-1911, https://doi.org/10.5194/isprs-archives-XLII-2W13-1907-2019.

Antonova, S., Kääb, A., Heim, B., Langer, M., Boike J., 2016. Spatio-temporal variability of X-band radar backscatter and coherence over the Lena River Delta, Siberia, Remote Sensing of Environment 182 (2016) 169-191.

Bach, K., Kahabka, H., Cerezo, F., Pérez, J.I.C., 2018. The TerraSAR-X / PAZ Constellation: Post-Launch Update, 12th European Conference on Synthetic Aperture Radar EUSAR 2018, June 4-7 2018, 765-767, Aachen, Germany.

Bovenga F., Wasowski J., Nitti D.O., Nutricato R., Chiaradia M.T. 2012. Using COSMO/SkyMed X-band and ENVISAT Cband SAR interferometry for landslides analysis, Remote Sensing of Environment 119,272-285.

Caló F., Notti D., Galve J.P., Abdikan S., Görüm T., Pepe A., Balik Şanli F., 2017. DInSAR Based Detection of Land Subsidence and Correlation with Groundwater Depletion in Konya Plain, Turkey. Remote Sensing, 9, 83.

Deguchi T., Kato M., Akcin H., Kutoglu H.S., 2007.Monitoring of mining induced land subsidence using L- and C-band SAR 
interferometry, 2007 IEEE International Geoscience and Remote Sensing Symposium, 10.1109/IGARSS.2007.4423253

Dogan, U., Y1lmaz, M., 2011. Natural and induced sinkholes of the Obruk Plateau and Karapınar-Hotamıs Plain, Turkey. Journal of Asian Earth Sci., 40, 496-508.

Du, Y., Xu, Q., Zhang, L., Feng, G., Li, Z., Chen, R.F., Lin, C.W. 2017. Recent Landslide Movement in Tsaoling, Taiwan Tracked by TerraSAR-X/TanDEM-X DEM Time Series. Remote Sens., 9, 353.

Hirayama, H., Sharma, R.C., Tomita, M. and Hara, K., 2019. Evaluating multiple classifier system for the reduction of saltand-pepper noise in the classification of very-high-resolution satellite images. International Journal of Remote Sensing, 40(7), 2542-2557.

Hisdesat 2019, PAZ Image Product Guide, PAZ-HDS-GUI-001 https://www.hisdesat.es/wp-content/uploads/2019/10/PAZHDS-GUI-001-PAZ-Image-Product-Guide-issue-1.1-.pdf

Lee H., 2010. Radargrammetry of high resolution synthetic aperture radar onboard KOMPSAT-5, 2010 IEEE International Geoscience and Remote Sensing Symposium, 10.1109/IGARSS.2010.5654153

Luo, Q., Zhou, G., Perissin, D., 2017. Monitoring of Subsidence along Jingjin Inter-City Railway with HighResolution TerraSAR-X MT-InSAR Analysis. Remote Sens.9, 717.

Milillo, P., Fielding, E.J., Schulz,W.H., Delbridge, B., Burgmann R., 2014. COSMO-SkyMed Spotlight Interferometry Over Rural Areas: The Slumgullion Landslide in Colorado, USA, IEEE Journal of Selected Topics in Applied Earth Observations and Remote Sensing, 7(7), 2919-2926.

Moreira, A., PratsIraola P., Younis, M., Krieger, G., Hajnsek, I., Papathanassiou K.P., 2013. A tutorial on synthetic aperture radar, IEEE Geoscience and Remote Sensing Magazine, 1(1), 643

Motagh M., Beavan J., Fielding E.J., Haghshenas M., 2013. Postseismic Ground Deformation Following the September 2010 Darfield, New Zealand, Earthquake From TerraSAR-X, COSMO-SkyMed, and ALOS InSAR, IEEE Geoscience and Remote Sensing Letters, 11(1), 186-190.

Nof, R.N., Baer, G., Ziv, A., Raz, E., Atzori, S., Salvi, S. 2013. Sinkhole precursors along the Dead Sea, Israel, revealed by SAR interferometry. Geology 41, 1019-1022.

Orhan, O., Yakar, M., Kirtiloglu, O.S. 2017. A Web Based Service Application for Visual Sinkhole Inventory Information System; Case Study of Konya Closed Basin, Konya Journal of Engineering Sciences, 5(1), 72-82.

Ozdemir, A., 2015. Investigation of sinkholes spatial distribution using the weights of evidence method and GIS in the vicinity of Karapinar (Konya, Turkey). Geomorphology, $245,40-50$.

Richter N., Poland M.P., Lundgren P.R. 2013. TerraSAR-X interferometry reveals small-scale deformation associated with the summit eruption of Kīlauea Volcano, Hawai'i, Geophysical Research Letters, 40, 1279-1283.

Schlund M., von Ponvet F., Hoekman D.H., Kuntz S., Schmullius C., 2014. Importance of bistatic SAR features from TanDEM-X for forest mapping and monitoring, Remote Sensing of Environment 151, 16-26.

Xue, F., Lv, X., Dou, F., Yun, Y., 2020. A review of time-series interferometric SAR techniques: A tutorial for surface deformation analysis, IEEE Geoscience and Remote Sensing Magazine, 8(1), 22-42. 